\title{
Ecological integrity of a peri-urban river system, Chiraura River in Zimbabwe
}

\author{
Beaven Utete*, Rutendo Maria Kunhe \\ Chinhoyi University of Technology Department of Wildlife and Safari Management P. Bag 7724, Chinhoyi
}

Email address:

beavenu@yahoo.co.uk(B. Utete), butete@cut.ac.zw(B. Utete)

\section{To cite this article:}

Beaven Utete, Rutendo Maria Kunhe. Ecological Integrity of a Peri-Urban River System, Chiraura River in Zimbabwe. Journal of Water Resources and Ocean Science. Vol. 2, No. 5, 2013, pp. 56-61. doi: 10.11648/j.wros.20130205.11

\begin{abstract}
Ecological integrity of a peri-urban river system facing a plethora of anthropogenic pressures was assessed through multivariate analysis of physicochemical parameters correlated to the resident macroinvertebrate community. Monthly collection of macroinvertebrates and concurrent measurement of the physical and chemical parameters (dissolved oxygen concentration, percentage saturation of oxygen, $\mathrm{pH}$, temperature, electrical conductivity and salinity) of water was done over a period of 5 months from November 2011- March 2012 in six sites across the Chiraura River. Macroinvertebrates were collected using the kick-net sampling technique, identified up to family level and enumerated at each site. Biodiversity indices were calculated for each site following the South African Scoring System version 5 (SASS5). A total of 1209 macroinvertebrates belonging to 49 families and11 orders were recorded in the Chiraura River. Most pollution sensitive taxa were found at sites 3 and 4 and the most pollution tolerant families were found at sites 1, 5 and 6 . Sites4 and 5 of Chiraura River were the least polluted. Unsustainable anthropogenic activities, including industrial, domestic and urban agricultural activities affects water quality of Chiraura River. This is mainly through run-off and increased effluent to the river making routine water quality monitoring imperative.
\end{abstract}

Keywords: Lotic System, Macroinvertebrates, River Health, SASS 5, Water Quality, Biomonitoring

\section{Introduction}

There is severe pressure on the quantity and quality of freshwater resources in Zimbabwe due to organic and inorganic pollution coupled with over abstraction $[1,2]$. This is especially true in the tributaries of hypereutrophic Lake Chivero, the main source of water for Harare, the capital city of Zimbabwe. The increasing rate of water pollution and abstraction in Lake Chivero catchment is a result of population growth, industrialization, and greater demand for irrigation and livestock production [3]. Chiraura River, a subtributary of Lake Chivero and a main source of water for the animals in Mukuvisi Woodlands Nature Reserve Area, is increasingly becoming susceptible to anthropogenic pollution, capturing the attention of the park management because of the important biodiversity held within the park.

Assessment of water quality in aquatic systems in Zimbabwe has tended to be biased towards the analysis of physicochemical properties, with biological monitoringlargely neglected [4]. Physicochemical analyses provide, at best, a fragmented overview of the state of aquatic systems, as sporadic or periodic sampling cannot reflect fluxes of effluent discharge. In contrast, biological monitoring, premised on the fact that living organisms are the ultimate indicators of environmental quality or ecosystem ecological integrity [5], gives a time-integrated indication of the water quality components because of the capacity of reflecting conditions that are not present at the time of sampling and analysis. The unique composite picture of ecosystem conditions provided by biological monitoring can only be replicated by intensive and expensive chemical monitoring studies. In addition, if the aim is to maintain the diversity and health of biological communities, it is appropriate to monitor aquatic communities themselves rather than only abiotic factors. Biological monitoring is now recognized as one of the most valuable tools available to environmentalists $[6,7,2]$.

Although macroinvertebrates are widely recognized as a biomonitoring tool, their application in river health assessments in Zimbabwe is of low precedence. To our knowledge, few available studies have only focused on some sections of rivers. These include the Mukuvisi River [4, 3], Nyaodza River in Kariba [8, 9] and Gwebi River [6]. 
Therefore this study seeks to contribute to the monitoring of peri-urban river health status in Zimbabwe. The objective of this study was to assess the ecological integrity of a peri-urban river system Chiraura River, facing a plethora of anthropogenic pressures correlating resident macroinvertebrates assemblages and abiotic factors.

\section{Materials and Methods}

\subsection{Study Area and Design}

The Chiraura River starts in the vlei behind the Honeydew farm near Greendale in the city of Harare. Upstream, it is fed by small rivulets which contribute substantially to the inflow. Burst sewer pipes, stream bank cultivation, urban run-off and informal motor vehicle industrial effluent in the catchment exposed the river to increasing levels of pollution. Headwater catchment area used to be characterised by wetlands, which are now being transformed into agricultural and settlement area. The transformation of the wetlands into agricultural and residential areas resulted in decreased flows, erosion and eutrophication in the Chiraura River. From this area, the river drains through Mukuvisi Woodlands Nature Reserve, a relatively undisturbed area. As it leaves the park, industrial effluent from the Msasa industry is discharged in the portion conjoined to the Mukuvisi River.

Six sites were selected along the Chiraura River based on the different land pattern use in the catchment. Site 1 $\left(17.826930{ }^{\circ} \mathrm{E} ; 31.1010^{\circ} \mathrm{S}\right)$ was located in the headwater region characterized by intense agricultural activities at the horticultural Honey Dew Farm; site 2 (17.826936 ${ }^{\circ} \mathrm{E}$; $31.1017^{\circ} \mathrm{S}$ ) covers the land adjacent to urban households where there is rampant dumping of solid waste and frequent burst sewer pipes. Site $3\left(17.826940{ }^{\circ} \mathrm{E} ; 31.1026\right.$ $\left.{ }^{\circ} \mathrm{S}\right)$ was located in the wetland adjacent to the Mukuvisi Woodlands Nature Reserve area. Sites 4 (17.826942 ${ }^{\circ} \mathrm{E}$; $\left.31.1030{ }^{\circ} \mathrm{S}\right)$ and $5\left(17.826942{ }^{\circ} \mathrm{E} ; 31.1032{ }^{\circ} \mathrm{S}\right)$ were located in the fenced section of the Mukuvisi Woodland Nature Reserve area. Site 6 (17.826942 ${ }^{\circ} \mathrm{E}$; $\left.31.1036{ }^{\circ} \mathrm{S}\right)$ was located at the confluence with the Mukuvisi River outside the Mukuvisi Woodland Nature Reserve area.

\subsection{Water Quality Sampling and Analyses}

At each site, dissolved oxygen (DO), Percentage saturation (\% saturation), electrical conductivity (EC), temperature, Total Dissolved Solids (TDS), and $\mathrm{pH}$ were measured using potable HACH electronic meters.

\subsection{Macroinvertebrates Sampling and Analysis}

At each site, macroinvertebrates collection and stream health inference was done following the SAAS 5 protocol [10]. Macroinvertebrates were sampled by disturbing stones (kick sampling technique) with feet for a total of 5 minutes at each site while the net was held downstream to collect the disturbed organisms. Macroinvertebrate samples were separated from the mud and detritus, identified to family level following studies by [11] and [12], sorted and counted before their release into the river.

\subsection{Data Analysis}

Analysis of variance (ANOVA) was used to compare means of physicochemical variables among sampling sites after testing for normality (Shapiro-Wilk test)and homogeneity of variance (Levene's test), and placed alongside local (Environmental Management Agency) and international (World Health Organisation) aquatic life threshold values. Pairwise comparison of the physicochemical values was done using the Tukeys 'test at $5 \%$ significance level. Kruskal Wallis test was used to compare means of (SASS and ASPT scores) among sampling sites. Pearson's correlation was used to determine the relationship between the calculated SASS and ASPT scores and measured physical and chemical water quality data. Correspondence analysis (CA) was used to examine the direct effect of the physical and chemical (pollutant) characteristics of the water on variation in taxon composition among sampling sites as a means of identifying possible indicator taxa that were sensitive to water pollution. ANOVA, Kruskal Wallis, Pearson's correlation, Levene's test and Shapiro-Wilk test were performed using Palaeontological Statistics (PAST) software version 2.16 [13]. CA was performed using the programme CANOCO 5 [14]

\subsection{Macroinvertebrate Diversityand Habitat Characterization}

Diversity of macroinvertebrate families were calculated using biotic indices. The Shannon Weaver and the Pielou evenness index were calculated to assess the diversity and richness of macroinvertebrates in each river using PAST software version 2.16 [13]. The ecological integrity of the river was assessed using the Habitat Assessment Matrix (HAM) strengthened by the Average Scores per Taxon at each site.

\section{Results}

\subsection{Physical-Chemical Parameters}

Physicochemical results measured in Chiraura River for the period (November 2011- March 2012) are summarized in Table 1 and a brief description of the highlights is done below:

The $\mathrm{pH}$ at most sites had values below 7 with the exception of site 4 and 5 with a mean $\mathrm{pH}$ of 7.1 and 7.3 respectively. There was a significant statistical difference (ANOVA; $\mathrm{p}<0.05$ ) in the $\mathrm{pH}$ values among sites. However, there was no significant (ANOVA; $p>0.05$ ) temporal (monthly) difference in $\mathrm{pH}$ values at all sites in the Chiraura River. All sites in the Chiraura River had mean pHvalues below the EMA and WHO ranges (Table 1).

Conductivity differed significantly (ANOVA, $\mathrm{p}<0.05$ ) among sampled sites in the Chiraura River. Pairwise 
comparison revealed significant differences (Tukeys' test, $\mathrm{p}$ $<0.05)$ in conductivity between sites $1\left(121.6 \mu \mathrm{S} / \mathrm{cm}^{1}\right)$ and $2\left(128.4 \mu \mathrm{S} / \mathrm{cm}^{1}\right)$ compared to sites $4\left(41.6 \mu \mathrm{S} / \mathrm{cm}^{1}\right), 5$ $\left(46.4 \mu \mathrm{S} / \mathrm{cm}^{1}\right)$ and $6\left(24.4 \mu \mathrm{S} / \mathrm{cm}^{1}\right)$. Significant (ANOVA, $\mathrm{p}$ $<0.05)$ monthly variation was observed in conductivity values at all sites. Mean conductivity values fell within the acceptable EMA and WHO limits (Table 1).

There was a significant difference (ANOVA, $\mathrm{p}<0.05$ ) in Total Dissolved Solids among the sampled sites in Chiraura River. Pairwise comparison shows that there were significant differences (Tukeys' test, $\mathrm{p}<0.05$ ) in TDS values between sites: 4 vs.1; 4 vs. 2 ; 4 vs. 3 and sites: 5 vs.1; 5vs. 2 and 5vs. 3. Significant (ANOVA; p <0.05) monthly/temporal differences in TDS values were observed across sites in the Chiraura River. Mean TDS values in the
Chiraura River were with the acceptable EMA and WHO values (Table 1). Dissolved oxygen levels did not differ significantly (ANOVA, $\mathrm{p}>0.05$ ) among sites sampled in Chiraura River during the study period. Sites 1, 2, 3 and-5 had DO concentrations below acceptable EMA and WHO threshold limits (Table 1).\% oxygen saturation: The six sites sampled had a significant difference (ANOVA, p < $0.05)$ in $\%$ oxygen saturation although there were no significant monthly variation at all sites. \% oxygen saturation was significantly high at site 6 (107.9) in the Chiraura River. Significant temporal (monthly) variation (Anova,p < 0.05) was observed in temperature, for all the sampled sites. Mean temperature values recorded at all sites in the Chiraura River fell within the acceptable EMA and WHO threshold values (Table 1).

Table 1: Physico- chemical (Mean \pm St Deviation.) variables measured at each sampling site in Chiraura River for the period (November 2011- March 2012). Note: Note: EMA = Environmental Management Agency. WHO = World Health Organisation.

\begin{tabular}{|c|c|c|c|c|c|c|}
\hline Site & $\operatorname{Temp}^{\circ} \mathrm{C}$ & DO(mg/L) & TDS(mg/L) & pH(units) & $\%$ Saturation & $\begin{array}{l}\text { Conductivity }(\mu \mathrm{S} / \\
\left.\mathrm{cm}^{1}\right)\end{array}$ \\
\hline \multirow[t]{2}{*}{1} & 23.8 & 4.7 & 192.8 & 6.9 & 50.3 & 121.6 \\
\hline & \pm 2.94 & \pm 1.11 & \pm 176.31 & \pm 0.21 & \pm 46.67 & \pm 22.143 \\
\hline \multirow[t]{2}{*}{2} & 23.7 & 4.9 & 201.4 & 4.2 & 50.5 & 128.4 \\
\hline & \pm 3.00 & \pm 0.55 & \pm 185.21 & \pm 3.85 & \pm 46.49 & \pm 43.39 \\
\hline \multirow[t]{2}{*}{3} & 19.4 & 4.9 & 290.8 & 5.8 & 74.1 & 63.4 \\
\hline & \pm 2.24 & \pm 0.33 & \pm 76.58 & \pm 0.2173 & \pm 2.66 & \pm 20.80 \\
\hline \multirow[t]{2}{*}{4} & 23.3 & 5.6 & 378.4 & 7.1 & 76.6 & 41.6 \\
\hline & \pm 3.06 & \pm 0.68 & \pm 79.13 & \pm 0.22 & \pm 12.75 & \pm 20.56 \\
\hline \multirow[t]{2}{*}{5} & 25.9 & 4.3 & 373.2 & 7.3 & 64.1 & 46.4 \\
\hline & \pm 1.26 & \pm 0.99 & \pm 94.16 & \pm 0.27 & \pm 15.06 & \pm 31.42 \\
\hline \multirow[t]{2}{*}{6} & 26.1 & 6.8 & 266.4 & 6.5 & 107.9 & 24.4 \\
\hline & \pm 2.97 & \pm 3.36 & \pm 176.92 & \pm 0.77 & \pm 52.83 & \pm 15.94 \\
\hline EMA & 35 & 5.0 & 1000 & $6-9$ & - & 1000 \\
\hline WHO & 27 & 5.0 & 1000 & $6.5-9$ & - & 1000 \\
\hline
\end{tabular}

\subsection{Macroinvertebrate Diversity and Habitat Characterization}

A total of 1209 macroinvertebrates belonging to 49 families and 11 orders were recorded in the Chiraura River. The highest number of taxa was recorded in the month of November (34) and the least number was in December (21 taxa) and January with 23 taxa. Shannon-Weaver diversity indices indicate that the month of November had the highest macroinvertebrate diversity $(\mathrm{H}=3.353)$ with December having the least diversity $(\mathrm{H}=2.791)$. Pielou Evenness' index also show that the month of November had the highest evenness of macroinvertebrate assemblages $\left(\mathrm{e}^{\wedge} \mathrm{H} / \mathrm{S}=0.8409\right)$ and December had the least evenness $\left(\mathrm{e}^{\wedge} \mathrm{H} / \mathrm{S}=0.7763\right)$. The families: Aeshnidae, Elmidae, Belostomatidae, Athereceridae, Chironomidae, Oligochaetae, and Coenagrionadae were the most abundant taxa in the Chiraura River and were present at all sites sampled in this study. Some families that cannot tolerate high levels of pollution such as the Tipulidae, Culicidae and Lestidae were found at sites 4 and 5 in the section where the river passes through the Mukuvisi Woodlands Nature Reserve.

There was a significant difference (Kruskal -ANOVA, $p$ $<0.05$ ) in the means of (SASS and ASPT scores) among sampling sites. No significant (Pearson test; $p>0.05$ ) relationship was observed between the calculated SASS and ASPT scores and most of the measured physical and chemical water quality data during this study except for total dissolved solids (TDS). The ecological integrity of the river was assessed using the Habitat Assessment Matrix strengthened by the Average Scores per Taxon at each site. The HAM scores show that the three upper headwater sections (sites1, 2 and 3) of the river were in a poor condition whilst the lower sections (sites 4 and 6) were in fair condition only site 5 was in good condition. Of particular note is site 6 where the river confluences with the 
Mukuvisi River that was also in fair- category (Table 3).

Table 2: Habitat characterization of the Chiraura River for the period Nov 2011-Mar 2012.

\begin{tabular}{cccc}
\hline Site & ASPT & HAM score & Condition \\
\hline 1 & 2.48 & 65 & poor \\
2 & 2.68 & 65 & poor \\
3 & 2.46 & 60 & poor \\
4 & 4.56 & 75 & fair \\
5 & 4.84 & 85 & good \\
6 & 4.06 & 70 & fair \\
\hline
\end{tabular}

\subsection{Influence of Environmental Variables on Macroinvertebrate Diversity}

Canonical Correspondence Analysis show that the first two axes account for $62.3 \%$ of the variation in macroinvertebrate diversity and distribution in the Chiraura River. Percentage oxygen saturation had a positive association with Hydracarina, Corixidae, Ancylidae, Tipuliidae, and Hydranidae. Dissolved Oxygen (DO) had a strong influence on the diversity of the Helodidade, Gyrinidae, Nepidae and Hydrophilidae more prominently at site 6. Electrical conductivity had a significant relation with the Potamonautidae, Planobidae, Baetidae and Ephydridaedistribution and diversity particularly at sites 1 , 2 and 3 in the Chiraura River (Figure 1). Temperature had a positive association with Notonectidae, Naucoridae, Belostomatidae, Culicidae, Lubellidae, Ceratopogonidae, Coenagrionadae, Dytiscidae and Oligochaeta. $\mathrm{pH}$ and Total Dissolved Solids (TDS) had a positive association with Elmidae, Pleidae, Dixidae, Chironomidae, Lymnaeidae, Lestidae, Gomphidae, Simullidae, Gerridae Vellidae and Pyralidae at site 4.

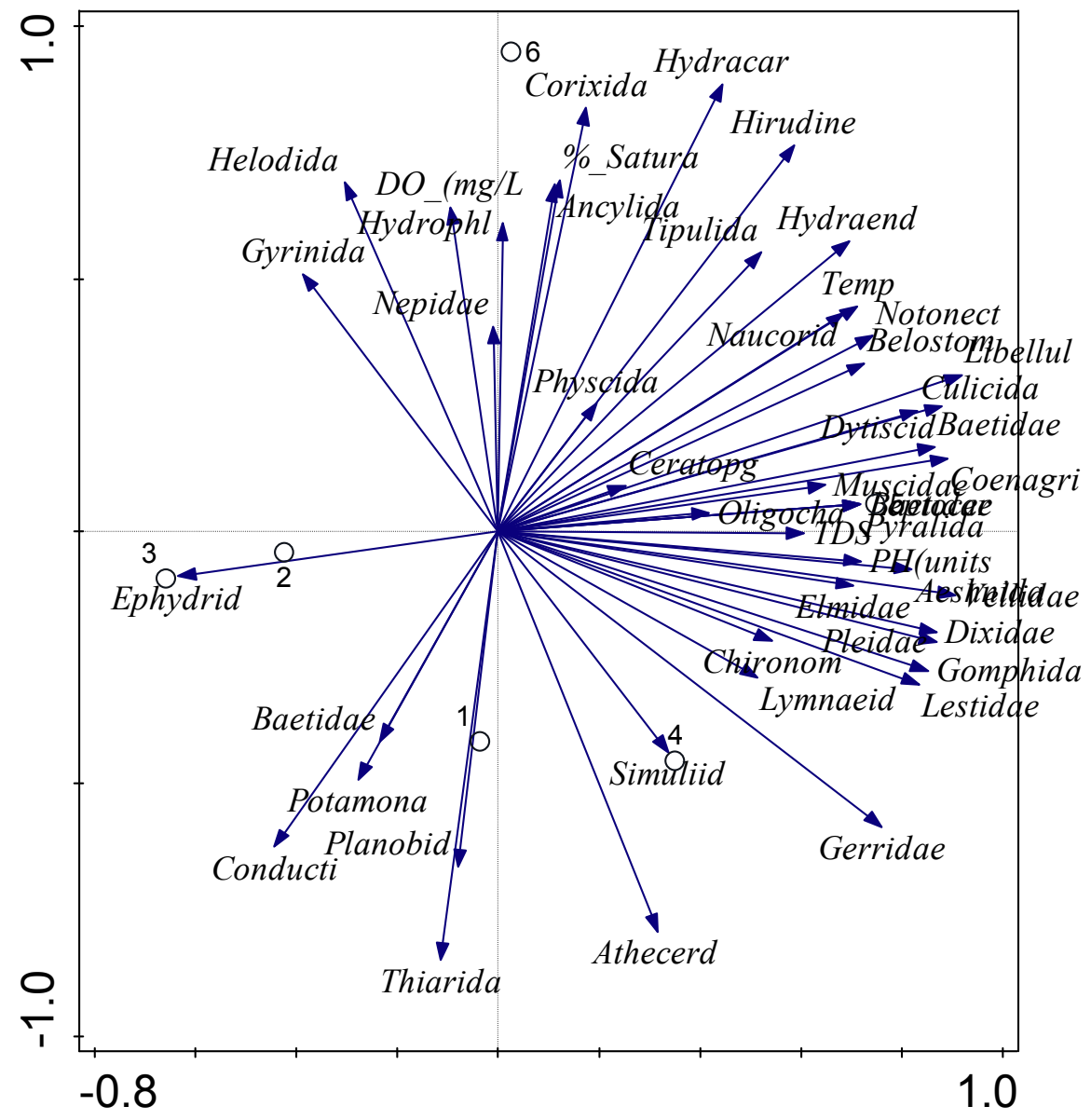

Figure 1.CA diagram showing relation between macroinvertebrates and environmental variables in Chiraura River

\section{Discussion}

Peri-urban rivers represent a pollution paradox as some sections are polluted and some sections have a functional self-purification capacity thus there is a tendency to exclude them in watershed management [7]. The peri-urban
Chiraura River has some sites (sites 1,2 and 3) which have poor water quality. These sites are located close to a horticultural farm and urban residential areas. The horticultural activities at these sites rely heavily on organic fertilizers, insecticides and pesticides which contribute to the pollution of the river. Sewage effluent discharges from 
adjacent urban households also contribute to the pollution of the river. Pollution tolerant families like the Chironomidae and Oligochaetae were abundant in sites 1, 2, 3 and 6 situated outside the Mukuvisi Woodlands Nature Reserve area. However, pollution sensitive taxa like the Trichoptera and Vellidae were observed at sites 4 and 5 which are located in the Mukuvisi Woodland nature reserve. The presence of tolerant families (e.g Potamonautidae, Planobidae, Thiaridae, Chironomidae in the more polluted sites (1, 2, 3 and 6) shows the usefulness of macroinvertebrates in indicating aquatic conditions [10]. However, absence/ presence of taxa is not only due to the abiotic conditions or anthropogenic impact but it might be just a natural phenomenon [15]. Unless baseline / reference conditions are established diversity indices can be misleading in indicating river conditions [5].

Using the HAM scores related to ASPT scores, sites 4 and 6 were in fair condition whilst site 5 was in good condition. This is because they are located in Mukuvisi Woodlands Nature Reserve area whose main objective is to preserve the pristine nature of the environment such that human and other environmental perturbations are low. There are no direct point sources of pollution. The good water quality in this section of the river appears suitable to support aquatic life because the highest macroinvertebrate taxa abundance (34 families) and diversity $(\mathrm{H}=4.3)$ was recorded in site 5 in the month of November. Results of this research reveal that there are some sections of the Chiraura River which are in fairly good condition and some sections of the river are polluted. This can be highly attributed to human activities such as agriculture, waste disposal and industrial effluent by surrounding industries as well as the environmental preservation by the Mukuvisi Woodlands Nature Reserve.

Water quality is an urgent problem in most African cities and Harare is no exception, such that there is need for urgent measures to reduce pollution flows into Chiraura River. These include proper treatment and diversion of sewage effluent the river, protection of wetlands in the Chiraura river section so that no human activities such as agriculture and waste disposal takes place as these activities immensely contribute to the degradation of the river. The long-term approach to curbing the negative impacts of heavy pollution on the health of the Chiraura River is the systematic removal of the major nutrients causing pollution [16]. Ways to achieve this goal include the use of a sediment scooper to physically remove sediments from the bottom of the river channel [17], including the nutrients contained within the sediments and river system, [2]. Proper construction, design, monitoring and maintenance of the effectiveness of riparian wetlands along polluted rivers such as the Chiraura River have the potential to curb eutrophication and in this study we suggest the use of the duckweed (Lemna spp) that has had success elsewhere to improve the self-purification capacity of rivers $[16 ; 18]$. Of concern is that the effects of poor water quality are very costly as they do not only affect human beings but also wildlife in Mukuvisi Woodlands Nature reserve where polluted water flows through it and is the main source of water for the animals.

\section{Acknowledgement}

Our special thanks to Dr Willie Nduku and $\mathrm{Mr}$ G. Nhokwara of WEZ and Mukuvisi Woodlands Association Nature Reserve\& Environment Centre respectively for allowing us to conduct this research in the Mukuvisi Woodlands Association Nature Reserve and Environment Centre, Dr Tamuka Nhiwatiwa for help with the field equipment and Professor Taurai Bere for his incisive comments and critique on the script during its drafting. $\mathrm{Mr}$ Tatenda Dalu, Edwin Tambara and Edwin Zingwe for their help in the field and Mrs Elizabeth Munyoro for the assistance with laboratory work.

\section{References}

[1] Nhapi, I. 2004. Options for wastewater management in Harare, Zimbabwe. Dphil Thesis. .Wagenigen University, The Netherlands.

[2] Ndebele RM. 2012. Biological monitoring and pollution assessment of the Mukuvisi River, Harare, Zimbabwe. Lake\& Reservoirs: Research Management. 17: 73-80.

[3] Magadza CHD.2003. Lake Chivero, A management case study. Lakes\& Reservoirs: Research Management. 8: 69-81.

[4] Phiri C. 2000. An assessment of the health of two rivers within Harare, Zimbabwe, on the basis of macroinvertebrate community structure and selected physicochemical variables. African Journal of Aquatic Science. 25: 134-141.

[5] Dallas HF. 1997. A preliminary evaluation of aspects of SASS (South African Scoring System) for the rapid bioassessment of water quality in rivers, with particular reference to the incorporation of SASS in a national bio monitoring programme. Southern African Journal of Aquatic Science. 23 (1):79-94.

[6] Moyo NAG and Phiri C. 2002. The degradation of an urban stream in Harare, Zimbabwe. African Journal of Ecology. 40: 401-404.

[7] Nhapi I, Siebel MA and Gijzen HJ. 2009. A proposal for managing wastewater in Harare, Zimbabwe. Water and Environment Journal. 20(2): 101-108.

[8] Chakona A, Phiri C and Day JA. 2009. Potential for Trichoptera communities as biological indicators of morphological degradation in riverine systems. Hydrobiologia. 621: 155167.

[9] Chakona A, Phiri C, Chinamaringa A and Muller N. 2009. Changes in biota along a dry land river in north-western Zimbabwe: declines and improvements in river health related to land use. Aquatic Ecology. 4: 1095-1106.

[10] Dickens C and Graham M. 2001. South African Scoring System (SASS) Version 5, Rapid Assessment Method for Rivers. Umgeni Water, Pietermaritzburg, South Africa. 
[11] Thirion C, Mox E and WoestR.1995. Biological monitoring of streams using SSS4 - A User Manual. Department Of Water Affairs and Forestry Institute for Water Quality. Studies. South Africa. Report NOOOO/OO/REQ/1195.p 46.

[12] Gerber A and Gabriel MJM. 2002. Aquatic invertebrates of South African rivers: Field guide. Resource Quality Services, Department of Water Affairs and Forestry, Pretoria, South Africa $150 \mathrm{pp}$.

[13] Hammer O, David A, Harper T and Ryan PD. 2001. Paleontological Statistics Software Package for Education and Data Analysis. Paleontological Museum, University of Oslo, Sars Gate1, 0562 Oslo, Norway.

[14] Te Braak CJF and Šmilauer P. 2012. Conoco reference manual and users' guide: Software for ordination (version5.0) Macro computer Power Ithaca New York. U.S.A.
[15] Chakona A. 2005. The Macroinvertebrate Communities of Two Upland Streams in Eastern Zimbabwe with Reference to the Impact of Forestry. Msc Thesis. University of Zimbabwe.

[16] Machena C. 1997.The pollution and self-purification of Mukuvisi River. In: Lake Chivero, a Polluted Lake (Eds.N. A. G. Moyo). 75-91pp. University of Zimbabwe Publishers, Harare, Zimbabwe.

[17] Cherry DS, Currie RJ, Soucek DJ, Latimer HA and Trent GC. 2001. An integrative assessment of a watershed impacted by abandoned mined land discharges. Environmental Pollution. 111: 377-388.

[18] Kjeldsen TR, Lundorf A and Rosbjerg D. 1999.Barrier to unstainable water resources management, A case study Hydro science Journal. 44:529-539. 